\title{
Potential of oil-lubricated cylindrical plastic gears
}

\author{
Christian HASL*, Christopher ILLENBERGER*, Peter OSTER*, Thomas TOBIE* and Karsten STAHL* \\ ${ }^{*}$ Gear Research Centre (FZG), Technical University of Munich (TUM), \\ Faculty of Mechanical Engineering, Boltzmannstr. 15, 85748 Garching, GERMANY \\ E-mail: fzg@fzg.mw.tum.de
}

Received: 14 April 2017; Revised: 3 December 2017; Accepted: 22 January 2018

\begin{abstract}
Bending strength of injection molded polyacetal test gears is investigated in back-to-back testing using oillubrication. To validate state of the art calculation methods, tooth geometries with a variable number of teeth are investigated, maintaining a constant center distance and transmission ratio. To enable testing on a constant level of tooth temperature for variable torque loads and speeds, occurring tooth temperatures are measured and considered in latter testing. Test results show that bending strength of tooth geometries with a higher number of teeth stand higher tooth root stresses acc. to VDI 2736, as the calculated tooth root stress is too high due to negligence of load-induced deflections. A modified method for calculating tooth root stress considers loadinduced deflections, allowing to trace back the failures of the different tooth geometries to a common stress level. Therefore, a possible approach to consider the actual contact ratio for tooth root stress calculation of steelplastic spur gear pairings is proposed.
\end{abstract}

Keywords : Cylindrical thermoplastic gears, Bending strength, Actual contact ratio, Polyacetal (POM)

\section{Introduction}

The widespread use of plastic gears is mainly connected with starved lubrication or even dry operation. Thereby, the most relevant damage mechanism, below thermal limits, is usually wear. In contrast, when using oil bath lubrication, significantly more power may be transmitted, due to reduced frictional energy and better heat dissipation, while wear can be reduced to a negligible level. Therefore, tooth root breakage gains importance. Previous theoretical studies indicate that load-induced deflections can cause lower tooth root stresses of certain gear geometries and therefore enable higher lifetimes compared to the expectations according the calculations of (VDI 2736, 2014). To prove this potential of bending strength of cylindrical plastic gears, back-to-back tests are conducted and evaluated.

\section{State of Knowledge}

(VDI 2736, 2014) summarizes methods to calculate load carrying capacity of thermoplastic cylindrical gears. Therein, the calculation of bending strength is based on (DIN 3990, 1987) Method C. This implies the assumption of rigid body teeth and therefore negligible deformation under load. (Fürstenberger, 2013) shows that load-induced deformations decisively affect the operational behavior and bending endurance of thermoplastic gears. To consider the deformation condition of a cylindrical gear pairing, the 'actual contact ratio' (also: 'real contact ratio') $\varepsilon_{\alpha, w}$ acc. to Eqn.(1) is taken as a basis.

$$
\begin{aligned}
& \varepsilon_{\alpha, w} \approx \varepsilon_{\alpha}+0,13 \cdot \sqrt{\frac{F_{t} / b}{\left(\varepsilon_{\alpha}+f_{\varepsilon \beta}\right) \cdot p_{e t} \cdot c^{\prime}}} \\
& \text { for } \beta=0^{\circ}: f_{\varepsilon \beta}=0 ; \text { for } \beta \neq 0^{\circ}: f_{\varepsilon \beta}=\varepsilon_{\beta} \leq 1
\end{aligned}
$$

(Fürstenberger, 2013) integrates the actual contact ratio in a modified method (Eqn. (2)) of the (VDI 2736, 2014)/ (DIN 3990, 1987) for calculating tooth root stress, resulting in a better correlation of bending strength calculation and 
experimental test results. For a normal pressure angle of $\alpha_{n}=20^{\circ}$, the modified form factor $Y_{F a}{ }^{\prime}$ and the modified stress correction factor $Y_{S a}{ }^{\prime}$ acc. to (Fürstenberger, 2013) remain equal to the unmodified values acc. to (VDI 2736, 2014). For other pressure angles see (Fürstenberger, 2013).

$$
\sigma_{F}^{\prime}=K_{F} \cdot Y_{F a}{ }^{\prime} \cdot Y_{S a}{ }^{\prime} \cdot Y_{\varepsilon}{ }^{\prime} \cdot Y_{\beta} \cdot \frac{F_{t}}{b \cdot m_{n}}
$$

The contact ratio factor $Y_{\varepsilon}{ }^{\prime}$ acc. to (Fürstenberger, 2013) is calculated as stated in Eqn.(3). The correction factor of the contact ratio factor $f_{Y \varepsilon, m i t}$ considers that the fatigue strength data acc. to (VDI 2736, 2014) contain the amount of loadinduced increase in contact ratio of the test gears. $f_{Y \varepsilon, m i t}$ is to be set to 1.2 when tooth root stress $\sigma_{F}^{\prime}$ is opposed to $\sigma_{F P}$ to calculate the bending strength.

$$
Y_{\varepsilon}^{\prime}=\left(0.25+\frac{0.75}{\varepsilon_{\alpha, w}}\right) \cdot f_{Y \varepsilon, m i t}
$$

(Thoma, 2011) identifies the number of teeth and the gear ratio as a significant factor influencing the geometric tendency of gear pairings to load-induced increase in contact ratio. Based on the equations acc. to (Thoma, 2011), an analyticiterative method is presented in (Hasl, 2016) to improve accuracy of the calculation of $\varepsilon_{\alpha, w}$. Furthermore, in (Hasl, 2017) it is shown, that for plastic gears the empirical factors contained in Eqn.(3), which originate in (DIN 3990, 1987), are adequate for $\varepsilon_{\alpha, \mathrm{w}} \leq 2$ while for $\varepsilon_{\alpha, \mathrm{w}}>2$ an adaption is beneficial. Therefore, a modified description of $Y_{\varepsilon}$ is proposed acc. to Eqn.(4) for tooth root stress calculation based on (DIN 3990, 1987) Method C respectively (VDI 2736, 2014) and (Fürstenberger, 2013). The method is called "ACORARS" (=actual contact ratio root stress; in short: "ACR").

$$
\begin{aligned}
& Y_{\varepsilon, A C R}=a_{A C R}+\frac{1-a_{A C R}}{\varepsilon_{\alpha, w}} \\
& a_{A C R}=\max \left(\min \left(\left(2.6-\varepsilon_{\alpha, w}\right) \cdot \frac{0.25}{0.8}, 0.25\right), 0\right)
\end{aligned}
$$

\section{Effect of the number of teeth on the increase in contact ratio}

The following considerations are based on the load-induced increase in contact ratio $\Delta \varepsilon_{w}$ which is calculated as the difference between the actual contact ratio $\varepsilon_{\alpha, w}$ and the transverse contact ratio $\varepsilon_{\alpha}$ acc. to Eqn.(5).

$$
\Delta \varepsilon_{w}=\varepsilon_{\alpha, w}-\varepsilon_{\alpha}
$$

In former works (Hasl, 2016 and 2017) the number of teeth is identified as a decisive factor especially for gear materials of significantly higher elasticities compared to steel. To illustrate the influence of the number of teeth on the actual contact ratio, $\Delta \varepsilon_{w}$ is calculated acc. to ACORA (Hasl, 2016) for tooth geometries of a variable number of teeth acc. to standard profile (DIN 867, 1986). Table 1 shows the underlying parameters while Fig. 1 illustrates the results of the calculations ('ACR'). $\Delta \varepsilon_{w}$ ascends with declining progression for an increasing number of pinion teeth. A higher number of teeth of the wheel effects an additional increase in $\Delta \varepsilon_{w}$. As the calculation of $\varepsilon_{\alpha, w}$ acc. to (Hasl, 2016) requires the implementation of the method in a computer program, due to iterations which may loop several times, a simplified estimation for standard profile tooth geometries is given by Eqn.(6). The results of the estimation acc. to Eqn.(6) are as well plotted in Fig. 1 and labeled as 'est.'.
Table 1: Tooth geometry for the variation of the number of teeth

\begin{tabular}{|l|c|c|}
\hline \hline & Pinion & Gear \\
\hline \hline Normal module & \multicolumn{2}{|c|}{ variable } \\
\hline Number of teeth & $16 \ldots 96$ & variable \\
\hline Transmission ratio $\left(\mathrm{z}_{2} / \mathrm{z}_{1}\right)$ & \multicolumn{2}{|c|}{$1 \ldots 6$} \\
\hline Load $F_{t} /\left(b \cdot m_{n}\right) \quad\left(\mathrm{N} / \mathrm{mm}^{2}\right)$ & \multicolumn{2}{|c|}{40} \\
\hline Normal pressure angle $(\mathrm{deg})$ & \multicolumn{2}{|c|}{20.0} \\
\hline Helix angle $(\mathrm{deg})$ & \multicolumn{2}{|c|}{0} \\
\hline (Tool) addendum factor & \multicolumn{2}{|c|}{1.25} \\
\hline (Tool) tip radius coefficient & \multicolumn{2}{|c|}{0.2} \\
\hline Tool) dedendum factor $\quad(\mathrm{mm})$ & \multicolumn{2}{|c|}{1.0} \\
\hline Tip diameter but by tool & \multicolumn{2}{|c|}{0} \\
\hline Profile correction factor & 210 & 1.3 \\
\hline Young's modulus $(\mathrm{GPa})$ & \multicolumn{2}{|c|}{} \\
\hline
\end{tabular}


$\Delta \varepsilon_{z i}\left(z_{1}, z_{2}\right)=0.15 \cdot \sqrt{z_{1}} \cdot\left(z_{2} / z_{1}\right)^{0.1}$

with $z_{1} \leq z_{2}$ and limited to external gears

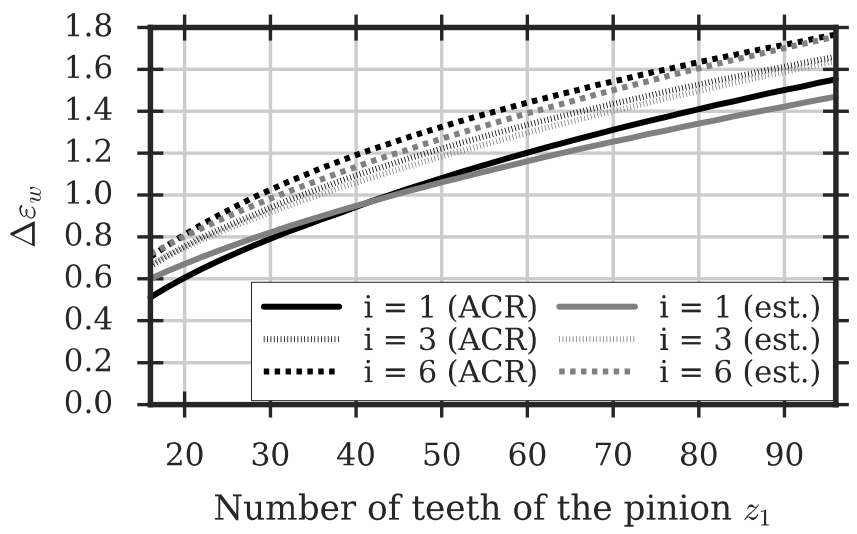

Fig. 1: Increase in contact ratio acc. to ACORA (Hasl, 2016) for different numbers of teeth and transmission ratios

\section{Test rig and test conditions}

All experimental tests are performed using a test rig, which is based on the standard configuration acc. to (DIN ISO 14635, 2006). Additionally, the test rig is equipped with a sensor shaft to measure the torque load of the test gear. Continuous monitoring of the torque load during testing allows the instant detection of 'loss of drive' conditions, caused by damages like tooth root breakage, and therefore exact determination of the number of cycles at failure. Fig. 2 shows the lubrication and cooling configuration of the test gear housing which is filled with FVA reference oil FVA3A (incl. 4\% Anglamol (A99)) which is classified as ISO-VG100. Pipes arranged in the oil bath are fed and drained by water, allowing cooling of the oil bath. Heating cartridges in the housing walls allow heating of the oil. Furthermore, to improve temperature control performance of the system, additional oil of an external oil tempering unit is injected into the meshing gears as common for injection lubrication. The oil outlet pipes outside of the housing are arranged to realize a barrage and therefore level the oil on the centers of the shaft axes as displayed in Fig. 2. Within the heating and cooling performance limits of the system, oil bath temperature is controlled with a maximum deviation of $5^{\circ} \mathrm{C}$ from the set value.

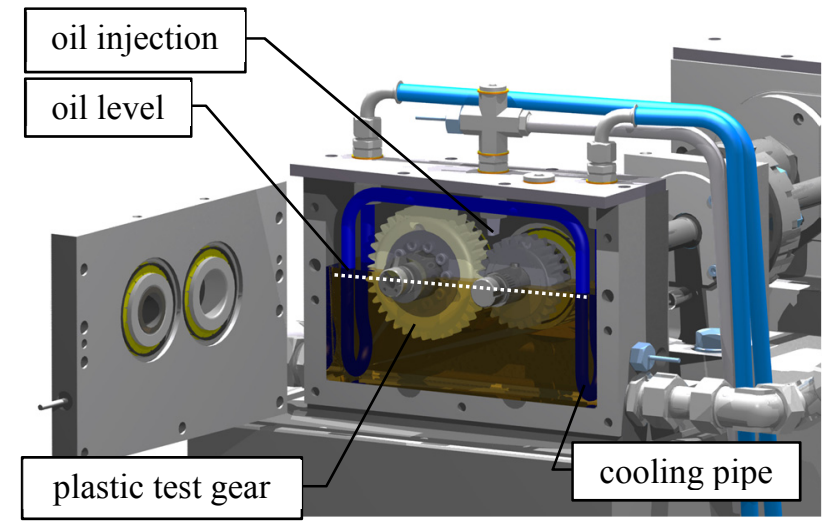

Fig. 2: Test gear housing of FZG test rig (DIN ISO 14635, 2006)

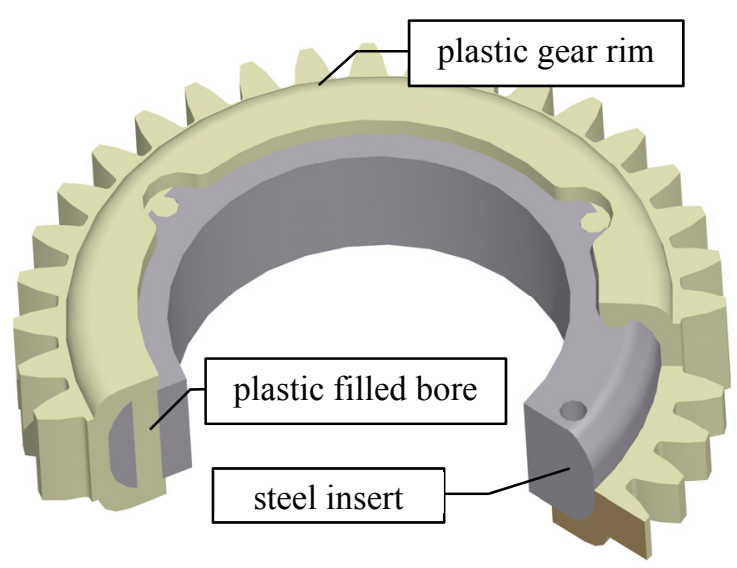

Fig. 3: Design of plastic test gears 


\section{Test Gears}

The test gears are manufactured by Werner Bauser GmbH using injection molding technology. Fig. 3 illustrates the test gear design. The gear rim is molded around a steel insert containing axial bores which are filled by plastic material during the manufacturing process, granting a form-fitting connection between both components.

Generally higher wall thicknesses are critical for injection molded parts regarding the tendency to cavities. However, preliminary testing revealed rim thicknesses of about $3 \cdot \mathrm{m}_{\mathrm{n}}$ being more appropriate, as smaller rim thicknesses may lead to rim breakage instead of tooth root breakage. Further information regarding the test gear design, manufacturing process and the underlying essential requirements are documented in (Hubert and Hasl, 2015). The gear geometries of the objected test gears are given in Table 2 . All subjected gear pairs feature a transmission ratio of $i=1.5$ and a center distance of $a=91,5 \mathrm{~mm}$. For manufacturing reasons, the plastic gears contain radii on the tip edges. The plastic test gears are paired with steel pinions. To enable smoother engagement, pinions of 'kst-B' and 'kst-C' contain a tip relief. The flank shape of pinions of 'kst-A' is not modified. During all tests the steel pinion is the driving gear.

Table 2: Gear geometries

\begin{tabular}{|c|c|c|c|c|c|c|}
\hline & \multicolumn{2}{|c|}{ kst-A } & \multicolumn{2}{|c|}{ kst-B } & \multicolumn{2}{|c|}{ kst-C } \\
\hline & Pinion & Gear & Pinion & Gear & Pinion & Gear \\
\hline Normal module & \multicolumn{2}{|c|}{1.0} & \multicolumn{2}{|c|}{2.0} & \multicolumn{2}{|c|}{3.0} \\
\hline Normal pressure angle (deg) & \multicolumn{2}{|c|}{20.0} & \multicolumn{2}{|c|}{20.0} & \multicolumn{2}{|c|}{20.0} \\
\hline Helix angle & 0 & & 0 & & 0 & \\
\hline Face width & 22 & 20 & 22 & 20 & 22 & 20 \\
\hline Number of teeth & 72 & 108 & 36 & 54 & 24 & 36 \\
\hline (Tool) addendum factor & 1.25 & 1.25 & 1.25 & 1.25 & 1.25 & 1.25 \\
\hline (Tool) tip radius coefficient & 0.3 & 0.46 & 0.25 & 0.39 & 0.25 & 0.33 \\
\hline (Tool) utilized dedendum & - & 0.78 & - & 0.74 & - & 0.7 \\
\hline (Tool) chamfer angle (deg) & - & 45 & - & 45 & - & 45 \\
\hline Tip diameter & 74.8 & 111.3 & 76.5 & 113.0 & 76.5 & 114.7 \\
\hline Usable tip diameter $(\mathrm{mm})$ & 74.8 & 111.0 & 76.5 & 112.4 & 76.5 & 113.9 \\
\hline Tip edge radius & - & 0.25 & - & 0.5 & - & 0.75 \\
\hline Tip relief amount & - & - & 45 & - & 65 & - \\
\hline Modification length $(\mathrm{mm})$ & - & - & 0.58 & - & 0.96 & - \\
\hline Base tangent length $(\mathrm{mm})$ & 29.4 & 41.8 & 27.8 & 46.2 & 32.3 & 41.8 \\
\hline Measured number of teeth & 10 & 14 & 5 & 8 & 4 & 5 \\
\hline Transverse contact ratio & \multicolumn{2}{|c|}{1.18} & \multicolumn{2}{|c|}{1.19} & \multicolumn{2}{|c|}{1.20} \\
\hline Material pairing & \multicolumn{2}{|c|}{ steel / plastic } & \multicolumn{2}{|c|}{ steel / plastic } & \multicolumn{2}{|c|}{ steel / plastic } \\
\hline
\end{tabular}

The steel pinions are made of case-hardened steel (16MnCr5) with grinded flanks resulting in roughnesses of $\mathrm{Ra}<0.6 \mu \mathrm{m}$ and qualities Q $\leq 7$ acc. to (DIN 3962, 1978). For the featured tests, the material of the plastic gears is homopolymer acetal (=POM) respectively Delrin ${ }^{\circledR} 100 \mathrm{NC} 010$ by DuPont ${ }^{\mathrm{TM}}$. The POM test gear qualities are about $\mathrm{Q} \approx 9 \ldots 12$ acc. to (DIN 3962, 1978).

\section{Measurements of Tooth Temperature}

The material properties, especially elasticity and fatigue, of thermoplastics decisively depend on temperature. As it is aimed to test gear specific fatigue strength to check the validity of existing temperature dependent fatigue strength data (VDI 2736, 2014), the level of material temperature during testing is of importance. Therefore, thermal sensors are applied in bores located near the middle of the chordal tooth thickness at the root as shown in Fig. 4. The sensor signal is routed through the hollow shaft to an inductive telemetry system (see Fig. 5) which enables continuous sampling of the temperature measurements during back-to-back testing. 


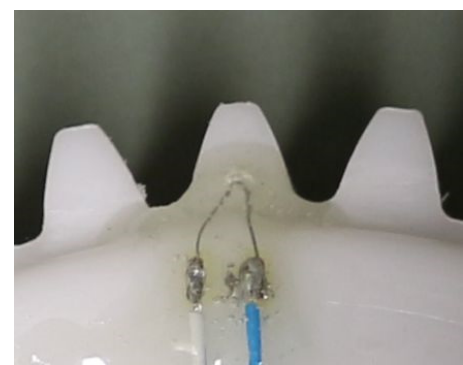

Fig. 4: Thermal sensor to measure tooth temperature

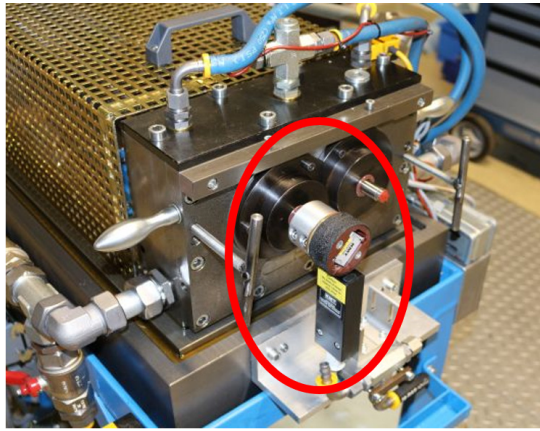

Fig. 5: Inductive telemetry system for measuring tooth temperature

To measure the tooth bulk temperature $\vartheta_{\text {tooth }}$, stage tests are conducted. Speed is varied under constant load and oil-sump temperature. The difference between oil-temperature and measured bulk temperature is evaluated and in the following referenced to as $\Delta \vartheta_{\text {tooth }}$. Speed is raised in stages from $400 \mathrm{rpm}$ to $3000 \mathrm{rpm}$ after the tooth bulk temperature has reached steady conditions. The results are shown in Fig. 6. Under constant load, $\Delta \vartheta_{\text {tooth }}$ rises with increasing imparted energy. The amount of heat resulting from higher slide-velocities in tooth contact and visco-elastic losses, due to tooth deflection under load, leads to higher $\Delta \vartheta_{\text {tooth }}$. Higher loads effect higher Hertzian stress and tooth deflections, resulting in increasing tooth temperatures. For all tooth geometries $\Delta \vartheta_{\text {tooth }}$ is within the same dimension of approximately 4 to $12 \mathrm{~K}$ at $3000 \mathrm{rpm}$ depending on the transferred torque. Additional tests at lower oil-temperatures are conducted in which comparable values for $\Delta \vartheta_{\text {tooth }}$ are monitored.

\section{Testing of Bending Strength}

Based on the measured tooth temperatures, the oil-sump temperature during testing is controlled to compensate the temperature difference $\Delta \vartheta_{\text {tooth }}$, allowing a constant temperature level for all load cases. Fig. 7 shows examples of occurring tooth root breakages for 'kst-A' and 'kst-B'. As a remarkable fact, the breakage areas of 'kst-C' in Fig. 8 show occurrences of cavities. Therefore, it has to be expected that this negatively affects the strength of this test gear variant. As the test gear design of variant ' $k s t-C$ ' as well as the corresponding manufacturing process was optimized several times, it may be concluded that the present scale of the teeth $\left(m_{n}=3 \mathrm{~mm}\right)$ characterizes a certain limit for injection molding manufacturing - at least for POM which has a significant tendency to shrinkage.

Fig. 9 shows the results of single-stage bending strength testing of all three tooth geometries at a tooth temperature level of $\vartheta_{\text {tooth }} \approx 80^{\circ} \mathrm{C}$. The markers indicate loss of drive failures by tooth root breakage. To indicate the mean tendency of the resulting fatigue strength, best-fit curves of the Wöhler function (Haibach, 2006) acc. to Eqn. (7) are included in the plots in Fig. 9.
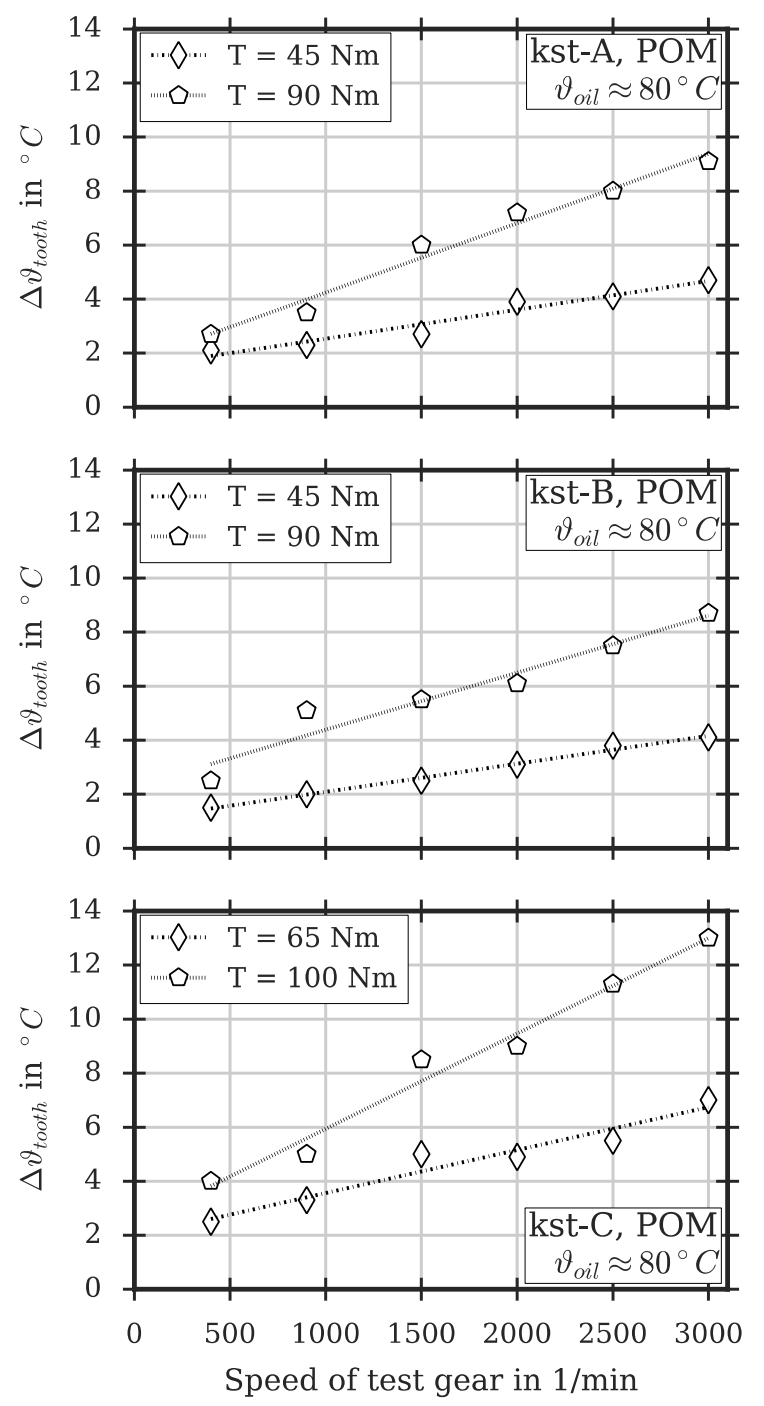

Fig. 6: Measured temperature difference $\Delta \vartheta_{\text {tooth }}$ between tooth bulk temperature and oil-temperature of kst-A,B,C 
$\lg (N)=a-b \cdot T$

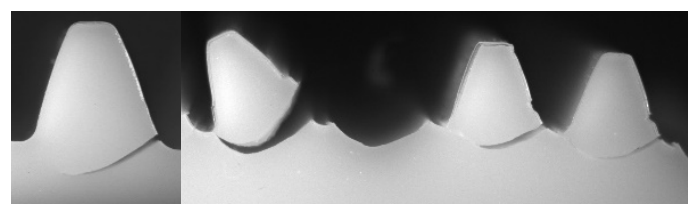

Fig. 7: left: kst-B, right: kst-A

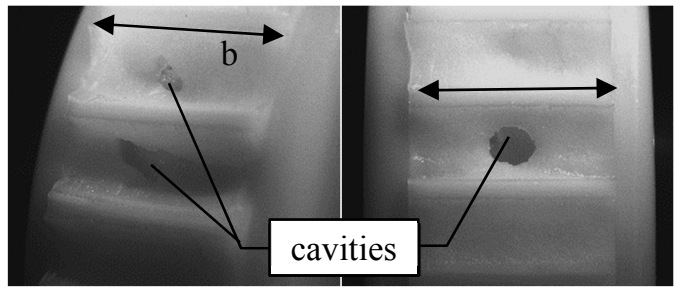

Fig. 8: Cavities in tooth root breakage area of 'kst-C'
To allow direct comparison of the test results with predictions of (VDI 2736, 2014), Fig. 9 contains the characteristics of the torque corresponding to a tooth root safety factor of $S_{F}=1$ considering the fatigue strength $\sigma_{\text {FlimN }}(N)$ for a temperature of $\vartheta_{F u ß}=80^{\circ} \mathrm{C}$ respectively $60^{\circ} \mathrm{C}$ acc. to (VDI 2736, 2014). The levels of 'kst-A' and 'kst-B' are well above the prediction of the (VDI 2736, 2014) while generally for an increasing number of cycles and thus decreasing load, the deviation between test results and the expectation acc. to (VDI 2736, 2014) is descending. This observation may be traced back to the decreasing influence of load-induced deflections with decreasing load. As 'kst-C' features the lowest number of teeth, and therefore is the least critical test gear variant considering the influence of the loadinduced increase in contact ratio, tolerable torque is significantly closer to the expectation acc. to (VDI 2736, 2014).

Regarding flank load-carrying capacity, (VDI 2736, 2014) states that for lubricated POM gears, an analysis is not necessary. Based on the experimental tests this can be confirmed insofar, as no 'pitting-like' damages on the flanks are observed. However, due to high amounts of load-induced deflections, plastic deformations in the areas of pre- and/or posterior meshing may occur. In the given experiments, the steel pinion being the driving gear, plastic deformations occur especially in the dedendum area of the thermoplastic gear due to the approaching tip edge of the steel pinion in the region of posterior meshing. For the examined POM test gears this damage mechanism limits lifetime only at comparatively high loads causing failures at about $10^{5}$ cycles or lower.

\section{Approximate Calculation of Tooth Root Stress Considering Load-induced Increase in Contact Ratio}

The load-carrying capacity level of 'kst-A' and 'kst-B', showing significantly higher life time than
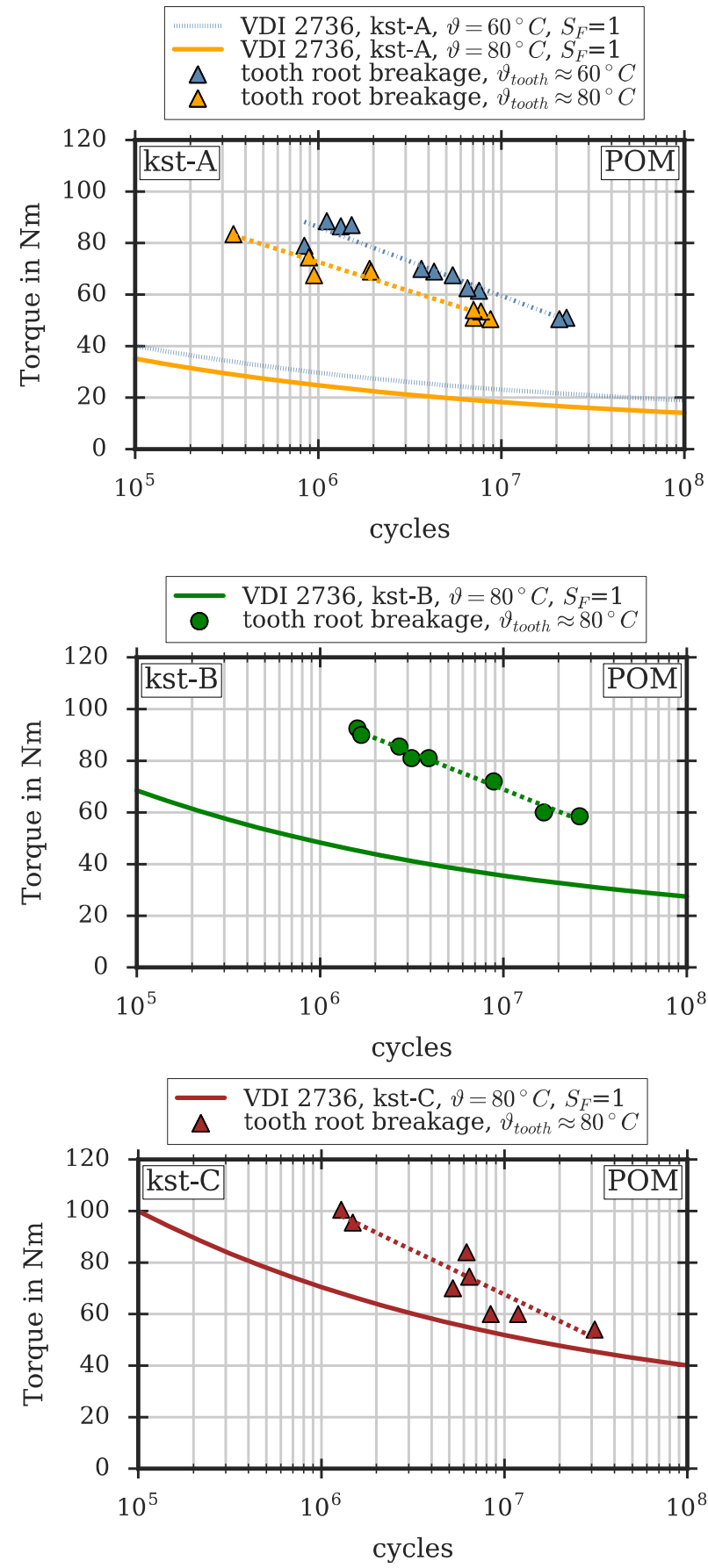

Fig. 9: Tooth root breakage (back-to-back testing) 'kst-A', 'kst-B' and 'kst-C' 
predicted, is traced back to the significant increase in actual contact ratio, especially in combination with the geometric tendency of higher numbers of teeth (Thoma, 2011) to an increase in contact ratio under load. As this effect is not considered by the empiric calculation of $\varepsilon_{\alpha, w}$ acc. to (Fürstenberger, 2013)/Eqn. (1), a modification based on Fig. 1 and Eqn. (6) is proposed. Therefore, it is aimed to seamlessly expand the scope of application of (Fürstenberger, 2013) by not changing the calculation results for gears with lower numbers of teeth. Eqn. (8) extends Eqn. (1) by adding an additional factor $f_{z i}$ to consider the effect of the number of teeth respectively the transmission ratio. $f_{z i}$ is limited to a minimum of 1 . It is calculated as the quotient of the 'number of teeth'-dependent increase in contact ratio of the focused gear pair to the one of a reference gear pair which is adequately characterized by Eqn. (1). For the reference gear pair a number of teeth of the pinion $z_{1}=36$ and a transmission ratio of $i=1.5$ are chosen. Only if $\Delta \varepsilon_{z i}\left(z_{1}, z_{2}\right)$ exceeds these limits, $\varepsilon_{\alpha, w, \text { mod }}$ is proportionally increased to consider the effect of the number of teeth.

$$
\begin{aligned}
& \varepsilon_{\alpha, w, \text { mod }} \approx \varepsilon_{\alpha}+0,13 \cdot \sqrt{\frac{F_{t} / b}{\left(\varepsilon_{\alpha}+f_{\varepsilon \beta}\right) \cdot p_{e t} \cdot c^{\prime}}} \cdot f_{z i} \\
& f_{z i}=\max \left(1, \frac{\Delta \varepsilon_{z i}\left(z_{1}, z_{2}\right)}{\Delta \varepsilon_{z i}(36,54)}\right)
\end{aligned}
$$

To take $\varepsilon_{\alpha, w, m o d}$ into account for calculating tooth root stress $\sigma_{F, \text { mod }}$ following Eqn. (2), only the contact ratio factor $Y_{\varepsilon}{ }^{\prime}$ is replaced by $Y_{\varepsilon, A C R}\left(\varepsilon_{\alpha, w, m o d}\right)$ (acc. to Eqn. (4)). For all other factors the recommendations of (VDI 2736, 2014) and (Fürstenberger, 2013) are maintained.

$$
\sigma_{F, \bmod }=K_{F} \cdot Y_{F a} \cdot Y_{S a} \cdot Y_{\varepsilon, A C R} \cdot Y_{\beta} \cdot \frac{F_{t}}{b \cdot m_{n}}
$$

The purpose of this approximation are standard profiles acc. to (DIN 867, 1986) of steel-plastic spur gear pairings. As effects of common flank profile modifications on contact ratio are little, compared to load-induced deflections, approximation of $\varepsilon_{\alpha, w}$ acc. to Eqn. (8) is usually adequate. Furthermore, corresponding to general practice for steel gears, consideration of modifications and deviations is possible via $K_{F \alpha}$ and $K_{F \beta}$ contained in $K_{F}$ (VDI 2736, 2014).

\section{Evaluation of the Test Results}

In Fig. 10, for each test, the nominal tooth root stress $\sigma_{F}$ acc. to (VDI 2736, 2014) as well as $\sigma_{F, \text { mod }}$ acc. to Eqn. (9) is calculated and plotted against the cycles when tooth root breakage occurred. As input parameters to solve Eqn. (2) respectively Eqn. (9) the following values apply: $K_{F}=1 ; Y_{\beta}=1 ; Y_{F a}=2$; $Y_{S a}=1.8$. It can be seen, that without consideration of the load-induced deflections acc. to (VDI 2736, 2014), with ascending numbers of teeth unrealistically high tooth root stresses are calculated. The levels of tolerable tooth root stress acc. to (VDI 2736, 2014) significantly vary for each investigated tooth geometry although the same material is used.

However, analog recalculation acc. to the herein

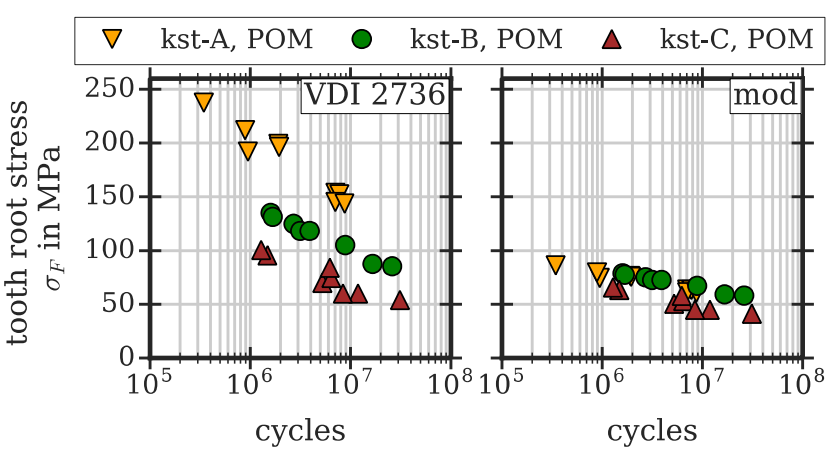

Fig. 10: $\sigma_{F}$ acc. to (VDI 2736, 2014) and $\sigma_{F, \bmod }$ corresponding to the cycles at failure of the test gears proposed, modified approach results in a common tooth root stress level for all investigated test gear geometries.

The cavities in geometry ' $\mathrm{kst}-\mathrm{C}$ ' reduce the load bearing cross-section in the tooth root area and may lead to stress concentrations. Therefore, it is plausible that its tolerable stress level is slightly lower compared to 'kst-A' and 'kst-B'. Hence, the good correlation of tolerable tooth root stress acc. to Eqn. (9) suggests the assumption that the main influence factors of the load-induced deflections are considered in adequate accuracy. 


\section{Potential and Challenges}

Regarding the evaluation of the test results, it is shown that the prediction of the sustainable torque acc. to (VDI 2736, 2014) is definitely on the safe side for tooth geometries with high numbers of teeth. This, however, can cause that feasibility checks of considered plastic gear applications with higher numbers of teeth, on the basis of (VDI 2736, 2014), may be negative due to the negligence of elasto-kinematic potential of certain tooth geometries regarding bending strength. This geometrically induced effect causes the power density of plastic gear pairs to rise with higher numbers of teeth due to the stronger tendency to load-induced increase in contact ratio.

On the other hand, when bending strength of new materials is investigated using test gears with certain numbers of teeth and the tests are evaluated using the formulas acc. to (VDI 2736, 2014), the effect is vice versa. If the in this way determined bending strength data are subsequently used to design gears with lower numbers of teeth compared to the test gears, the results acc. to (VDI 2736, 2014) calculation will be on the unsafe side.

Beyond this, potential is seen in the transmittable power of oil-lubricated plastic gears. (Fürstenberger, 2013) describes dry-running tests which are comparable regarding scale, as the installation space (center distance a $=91.5 \mathrm{~mm}$; transmission ratio $i=1.5$; face width $b=20 \mathrm{~mm}$ ) is identical. He shows that a conventional steel-polyamide tooth geometry can transmit a maximum power of about $4 \mathrm{~kW}$ without instant thermal damage. Using oil-lubrication (and 'cooling') most herein presented tests took place at a test gear revolution speed of 2200 to 3000 rpm meaning a continuous power of up to almost $30 \mathrm{~kW}$ which is e.g. in the dimension of the driving power of mini-vehicles.

\section{Summary}

As elongation at yield of thermoplastic materials is about ten times higher compared to steel, neglecting the effect of load-induced deformation can lead to significant underestimation of the load-carrying potential of plastic gears, at least for specific tooth geometries. To validate state of the art bending strength calculation (VDI 2736, 2014) - especially for highly loaded, oil-lubricated gears - injection molded test gears with different numbers of teeth are investigated in back-to-back testing. The center distance and transmission ratio is kept constant. As material, POM is used, which has been and still is a common material for plastic gears for decades and therefore is considered appropriate as a reference material.

The test results confirm that load-induced deflections are a significant factor. With increasing number of teeth the deviation between actual stress and calculated stress acc. to (VDI 2736, 2014) rises. The test gear with the highest number of teeth transfers more than twice the torque expected acc. to (VDI 2736, 2014). To consider this effect, a modification of the tooth root stress calculation acc. to (Fürstenberger, 2013) is proposed. Recalculating the root stresses of all performed gear tests, based on this approach, results in a common stress level for all examined tooth geometries. Consequently, it can be concluded, that the method is adequate to consider the effect of the load-induced deflections of steel-POM pairings based on a standard rack profile (DIN 867, 1986).

\section{Outlook}

Considering the results of further experimental tests, the aim is to derive a modified method to calculate bending strength of highly loaded (= oil-lubricated) thermoplastic gears. This includes the validation of existing fatigue strength data $\left(\sigma_{\text {FlimN }}\right.$ acc. to (VDI 2736, 2014)) as well as investigations on the bending strength of new materials which are not yet contained in (VDI 2736, 2014).

\section{Acknowledgements}

FZG would like to thank German Research Foundation (DFG, Deutsche Forschungsgemeinschaft, HO 1339/47-1) for their kind sponsorship of this research project focusing on bending strength of thermoplastic gears. Furthermore, we kindly thank Werner Bauser GmbH (Siemensstr. 2; D-78564 Wehingen) for the development and manufacturing of the injection molded test gears. We also thank DuPont ${ }^{\mathrm{TM}}$ for providing the raw material and support in conjunction with the manufacturing process of the test gears. 
Nomenclature

\begin{tabular}{|c|c|c|}
\hline$a$ & $m m$ & center distance \\
\hline$a_{A C R}$ & - & auxiliary factor to calculate $Y_{\varepsilon, A C R}$ \\
\hline$b$ & $m m$ & face width \\
\hline$\varepsilon_{\alpha}$ & - & transverse contact ratio \\
\hline$\varepsilon_{\alpha, w}$ & - & actual contact ratio \\
\hline$\Delta \varepsilon_{w}$ & - & load-induced increase in $\varepsilon_{\alpha, w}$ \\
\hline$\Delta \varepsilon_{z i}$ & - & approx. increase in actual contact ratio due to the numbers of teeth \\
\hline$f_{Y \varepsilon, m i t}$ & - & correction factor of $Y_{\varepsilon}^{\prime}$ acc. to (Fürstenberger, 2013) \\
\hline$f_{z i}$ & - & correction factor of $\Delta \varepsilon_{w}$ \\
\hline$F_{t}$ & $N$ & tangential load \\
\hline$i$ & - & transmission ratio $\left(=z_{2} / z_{1}\right)$ \\
\hline$K_{F}$ & - & factor for tooth root load (VDI 2736, 2014) \\
\hline$K_{F \alpha}$ & - & face factor (VDI 2736, 2014), (DIN 3990, 1987) \\
\hline$K_{F \beta}$ & - & width factor (VDI 2736, 2014), (DIN 3990, 1987) \\
\hline$m_{n}$ & $m m$ & normal module \\
\hline$N$ & - & number of cycles \\
\hline$\sigma_{F}^{\prime}$ & $M P a$ & tooth root stress acc. to (Fürstenberger, 2013) \\
\hline$\sigma_{F, \bmod }$ & $M P a$ & modified tooth root stress \\
\hline$\sigma_{\text {FlimN }}$ & $M P a$ & fatigue strength (VDI 2736, 2014) \\
\hline$\sigma_{F P}$ & $M P a$ & permissible root stress (VDI 2736, 2014) \\
\hline$\vartheta_{F u ß}$ & ${ }^{\circ} \mathrm{C}$ & root temperature (VDI 2736, 2014) \\
\hline$\vartheta_{\text {tooth }}$ & ${ }^{\circ} \mathrm{C}$ & measured tooth bulk temperature \\
\hline$\Delta \vartheta_{\text {tooth }}$ & $\mathrm{K}$ & temperature difference between $\vartheta_{\text {tooth }}$ and oil-temperature \\
\hline$T$ & $\mathrm{Nm}$ & torque load of test gear \\
\hline$Y_{\varepsilon, A C R}$ & - & modified contact ratio factor \\
\hline$Y_{\beta}$ & - & helix angle factor (VDI 2736, 2014) \\
\hline$Y_{\varepsilon}^{\prime}$ & - & contact ratio factor acc. to (Fürstenberger, 2013) \\
\hline$Y_{F a} / Y_{F a}{ }^{\prime}$ & - & form factor (VDI 2736, 2014)/ (Fürstenberger, 2013) \\
\hline$Y_{S a} / Y_{S a}{ }^{\prime}$ & - & stress correction factor (VDI 2736, 2014)/ (Fürstenberger, 2013) \\
\hline$z_{1,2}$ & - & number of teeth (pinion, wheel) \\
\hline
\end{tabular}

\section{References}

DIN 867:1986-02, Bezugsprofile für Evolventenverzahnungen an Stirnrädern.

DIN 3990:1987-12, Tragfähigkeitsberechnung von Stirnrädern.

DIN 3962:1978-08, Toleranzen für Stirnradverz.

DIN ISO 14635-1:2006-05 Gears - FZG test procedures - Part 1: FZG test method A/8,3/90 for relative scuffing loadcarrying capacity of oils.

Fürstenberger, M. Betriebsverhalten verlustoptimierter Kunststoffzahnräder. FZG / TU München: Ph.D. thesis, 2013. Hachmann, H. and Strickle, E. Polyamide als Zahnradwerkstoffe. Konstruktion (Sonderdruck). 1966, Vol. 18 / 3.

Haibach, E. Betriebsfestigkeit. Berlin Heidelberg: Springer-Verlag, 2006. ISBN: 3-540-29363-9.

Hasl, C., et al. Verfahren zur Berechnung der Überdeckung unter Last von Kunststoffstirnrädern. Forsch Ingenieurwes. doi:10.1007/s10010-016-0207-8, 2016.

Hasl, C., et al. Method for calculating the tooth root stress of plastic spur gears meshing with steel gears under consideration of deflection-induced load sharing. Mechanism and Machine Theory. currently in publication, 2017.

Hubert, T., Hasl, C., et al. Requirements of injection molded plastic test gears for back-toback and pulsator testing. VDI, International Conference on Gears. pages 1183-1190, 2015, Vol. 2, ISBN 978-3-18-092255-3.

Thoma, F. Lastübertragung im verformten System Lager-Welle-Zahnrad. FZG / TU München : Ph.D. thesis, 2011.

VDI 2736:2014-06, Blatt 2, Cylindrical gears - Calculation of the load-carrying capacity. 